\title{
Evaluation of Pulmonary Edema: Stereological versus Gravimetrical Analysis
}

\author{
Antonia Fehrenbach $^{a}$ H. Fehrenbach ${ }^{b} \quad$ T. Wittwer $^{c}$ M. Ochs ${ }^{a}$ T. Wahlers ${ }^{c}$ \\ J. Richter ${ }^{\mathrm{a}}$ \\ aDivision of Electron Microscopy, Center of Anatomy, University of Göttingen, \\ bInstitute of Pathology, University Clinic Carl Gustav Carus, TU Dresden, and \\ 'Department of Cardiothoracic and Vascular Surgery, Friedrich Schiller University Jena, Germany
}

\section{Key Words}

Lung · Ischemia reperfusion injury - Wet-to-dry weight ratio . Transplantation

\begin{abstract}
Assessment of lung edema by gravimetrical analysis is a standard method to evaluate the severity of experimentally induced ischemia/reperfusion (IR) injury. The aim of this study was to compare gravimetrical assessment of pulmonary edema with a stereological approach which allows for qualitative and quantitative distinction between intravascular and edematous fluids by light microscopy. Eight experimental groups which differed in mode of preservation, ischemic storage and pharmacological treatments were studied in an extracorporeal rat lung model. Analysis of the pooled data showed that the wet/dry ratio values mainly reflected the amount of intra-alveolar edema $\left(r_{s}=0.442 ; p=0.0057\right)$ but only stereological assessment of edema formation revealed differences depending on the treatment used. Only stereological data correlated significantly with oxygen tension measured at the end of reperfusion $\left(r_{s}=-0.530 ; p=\right.$ $0.0009)$. We conclude that gravimetry is of minor functional importance compared to assessment by stereological methods which prove to be a reliable and efficient tool for the evaluation of IR injury in the different experimental settings.
\end{abstract}

Copyright $(2001$ S. Karger AG, Basel

\section{Introduction}

Pulmonary edema is a characteristic manifestation of acute lung injury of different etiology [1]. In lung transplantation, the extent of noncardiogenic edema formation determines the severity of the pulmonary reimplantation response which always occurs in the early reperfusion period [2].

In the last two decades, progress in understanding the biochemical and immunological mechanisms leading to pulmonary edema has been achieved (as reviewed by Matthay and Ingbar [1]). In morphology, pulmonary edema is defined as a pathological increase in extravascular lung water which results from an imbalance between fluid transvascular filtration and clearance [3, 4]. The lung interstitium and alveoli are the main sites of increase in extravascular lung water. Understanding the mechanisms behind the formation of pulmonary edema is crucial for improvements to the clinical setting [5].

The wet-to-dry weight (w/d) ratio represents a standard criterion to assess the quality of experimental lung preservation. The determination of the $\mathrm{w} / \mathrm{d}$ ratio by gravimetrical analysis, however, is paralleled by complete destruction of the tissue impeding any further analysis which could give additional information on pathological changes. On the other hand, scoring criteria to assess the degree of edema formation based on the examination of lung tissue by light microscopy can provide valuable information on the degree as well as the anatomic distri-

\begin{tabular}{ll}
\hline KARGER & ( 2001 S. Karger AG, Basel \\
0014-312X/01/0334-0270\$17.50/0 \\
$\begin{array}{l}\text { Fax +4161306 12 34 } \\
\begin{array}{l}\text { E-Mail karger@karger.ch } \\
\text { www.karger.com }\end{array}\end{array}$ & $\begin{array}{l}\text { Accessible online at: } \\
\text { www.karger.com/journals/esr }\end{array}$
\end{tabular}

Antonia Fehrenbach

Division of Electron Microscopy, Center of Anatomy, University of Göttingen Kreuzbergring 36

D-37075 Göttingen (Germany)

Fax+49551397004, E-Mail afehren1@gwdg.de 
Table 1. Treatments performed in the different experimental groups

\begin{tabular}{|c|c|c|c|c|c|c|c|c|c|}
\hline & $\mathrm{Co}$ & $\mathrm{EC}$ & CE15 & anCE & CENO & $\mathrm{reCE}$ & anPX & PXNO & rePX \\
\hline Animals & 5 & 5 & 5 & 5 & 5 & 5 & 5 & 5 & 5 \\
\hline Antegrade & & $\mathrm{x}$ & $\mathrm{x}$ & $\mathrm{x}$ & $\mathrm{x}$ & & $\mathrm{x}$ & $\mathrm{x}$ & \\
\hline Retrograde & & & & & & $\mathrm{x}$ & & & $\mathrm{x}$ \\
\hline Storage at $10^{\circ} \mathrm{C}$ & & $\mathrm{x}$ & & $\mathrm{x}$ & $\mathrm{x}$ & $\mathrm{x}$ & $\mathrm{x}$ & $\mathrm{x}$ & $\mathrm{x}$ \\
\hline Storage at $15^{\circ} \mathrm{C}$ & & & $\mathrm{x}$ & & & & & & \\
\hline NO donor & & & & & $\mathrm{x}$ & & & $\mathrm{x}$ & \\
\hline Prostacyclin & & $\mathrm{x}$ & $\mathrm{x}$ & & & & & & \\
\hline
\end{tabular}

$\mathrm{Co}=$ Control $; \mathrm{EC}=$ Eurocollins $; \mathrm{CE}=$ Celsior $; \mathrm{PX}=$ Perfadex; an = antegrade; re $=$ retrograde; $\mathrm{NO}=$ nitroglycerin . bution of edema, and are therefore suggested to be used as an adjunct to physiological studies [6,7].

Using a stereological approach which allows for quantification and establishment of the distribution pattern of pulmonary edema in the distinct lung compartments by light microscopy $[8,9]$, we previously studied edema formation after ischemia and reperfusion in an extracorporeal rat lung model [10-13]. Stereological quantitation of edema but not the analysis of w/d ratios detected significant differences among the experimental groups and relationships between stereology and hemodynamic and respiratory parameters could be established $[11,14,15]$.

Based on these findings, this study was designed to compare gravimetrical analysis of lung edema with the stereological assessment of edema formation in the distinct lung compartments. We further proposed that interstitial edema, which forms a relatively small pool compared to the alveolar and intravascular compartments, is underestimated by gravimetry.

A collection of data referring to lung edema was pooled from 8 experimental groups which differed in mode of preservation, ischemic storage and pharmacological treatments. The w/d ratios were determined, edematous compartments were characterized by light and electron microscopy and volume fractions of intra-alveolar and interstitial edema as well as intravascular water were estimated at the light-microscopical level by standard stereological means.

\section{Materials and Methods}

Animals

Male inbred Sprague-Dawley rats $\left(\mathrm{Crl}: \mathrm{CD}^{\circledR}\right.$, Charles River, Sulzfeld, Germany) with a mean body weight of $445 \pm$ (SD) $28 \mathrm{~g}$ were anesthetized intraperitoneally with Pentobarbital (Narcoren, Rhône Mérieux, France, $12 \mathrm{mg} / 100 \mathrm{~g}$ body weight), intubated by tracheosto- my, and heparinized via the vena cava inferior (100 IU). All animals received humane care in compliance with the German animal protection legislation and consent was given by the appropriate governmental and institutional agencies.

\section{Experimental Design}

Data referring to the accumulation of lung water were pooled from 40 animals of 8 experimental groups (5 lungs per group). Organ preservation was either performed with Eurocollins (EC, Fresenius, Bad Homburg, Germany) reduced to $40 \mathrm{mmol} \mathrm{K}^{+}$or Perfadex (PX = low potassium dextran, vitro life, Gothenburg, Sweden) or Celsior (CE, Imtix, Pasteur Mérieux, Lyon, France). The route of flush perfusion (antegrade/retrograde), storage temperatures during ischemia $\left(10\right.$ or $\left.15^{\circ} \mathrm{C}\right)$ and additives to the preservation solution such as prostacyclin $(6 \mu \mathrm{g} / 100 \mathrm{ml}$; Epoprostenol; Flolan; Wellcome) and nitroglycerin $(\mathrm{NO} ; 0.1 \mathrm{mg} / \mathrm{ml})$ in the different groups are summarized in table 1 .

\section{Lung Preparation and Perfusion}

Operation and excision of the heart-lung block was performed as described recently [13]. During surgery, the animals were ventilated with room air at a tidal volume of $5 \mathrm{ml}$ and a respiration rate of 40 breaths $/ \mathrm{min}$ with a positive end-expiratory pressure (PEEP) of $3 \mathrm{~cm}$ $\mathrm{H}_{2} \mathrm{O}$. Lungs were flushed with $20 \mathrm{ml}$ of preservation solution either via the pulmonary artery (antegrade) or via the left atrium (retrograde) at a hydrostatic pressure of $20 \mathrm{~cm} \mathrm{H}_{2} \mathrm{O}$ and stored for $4 \mathrm{~h}$ at either 10 or $15^{\circ} \mathrm{C}$ (see experimental design and table 1 ). This was followed by a 50 -min reperfusion via the pulmonary artery with Krebs-Henseleit buffer $\left(8.0 \mathrm{ml} / \mathrm{min}\right.$ at $\left.37^{\circ} \mathrm{C}\right)$ containing bovine red blood cells (hematocrit of $38-40 \%$ ) using a quattro head roller pump (Mod-Reglo-Digital, Ismatec, Zürich, Switzerland).

\section{Gravimetry}

w/d ratio was determined for the left reperfused lungs. Lungs were weighed (wet value) immediately after reperfusion (R300S, Sartorius, Göttingen, Germany), and after storage for $24 \mathrm{~h}$ at $95^{\circ} \mathrm{C}$ (dry value).

\section{Oxygen Tension}

Blood gases were determined in 10-min intervals during a 50-min period of reperfusion [13]. The $\mathrm{pO}_{2}$ measured in the effluate of the left atrium was defined as arterial $\mathrm{pO}_{2}\left(\mathrm{paO}_{2}\right)$, and the $\mathrm{pO}_{2}$ from the deoxygenated blood reservoir as venous $\mathrm{pO}_{2}\left(\mathrm{pvO}_{2}\right)$. For assessment 
of the oxygenation ability of the reperfused lungs oxygen tension was calculated ( $\left.\left[\mathrm{paO}_{2}-\mathrm{pvO}_{2}\right]\right)$. The oxygen tension at the end of reperfusion was correlated with data from stereological and gravimetrical assessments of lung water.

\section{Fixation}

After reperfusion, the right lungs were fixed by vascular perfusion for 15-20 min via the pulmonary artery at a hydrostatic pressure adjusted to $15 \mathrm{~cm} \mathrm{H}_{2} \mathrm{O}$ and at constant airway pressure of $12 \mathrm{~cm}$ $\mathrm{H}_{2} \mathrm{O}$. For optimal preservation of the ultrastructure, control lungs $(\mathrm{n}=5)$ were fixed in situ immediately before excision. The fixative used was a mixture of $1.5 \%$ glutaraldehyde and $1.5 \%$ paraformaldehyde in $0.15 \mathrm{M}$ HEPES buffer (300 mosm $/ \mathrm{kg}$ buffer osmolarity at $\mathrm{pH}$ 7.35) (Merck, Darmstadt, Germany). At the end of perfusion fixation, the main right bronchus and pulmonary artery were tightly clamped and the lungs were stored in cold fixative for 5-7 day until further processing.

\section{Sampling}

After determination of the lung volume by fluid displacement, systematic uniform random sampling of lung tissue was performed at each step according to standard methods [9]. This is a prerequisite for samples that are representative of the whole organ which thus can be analyzed by stereological methods. Using a tissue slicer the organ was cut into 10-12 horizontal slices of $3 \mathrm{~mm}$ thickness. Starting with a random number, one slice was collected for electron microscopy (EM), the next for plastic and the third for paraffin embedding.

\section{Tissue Processing and Microscopy}

Processing of the tissue blocks for stereological analysis was performed as described earlier [11]. In brief, tissue blocks were osmicated in $1 \% \mathrm{OsO}_{4}$ in $0.1 \mathrm{M}$ cacodylate buffer for $2 \mathrm{~h}$ and stained en bloc overnight with semisaturated aqueous uranyl acetate to stabilize phospholipids. For histological analysis, samples were dehydrated in an ascending series of alcohols and whole tissue slices were embedded in a methacrylate resin (Technovit 7100; Kulzer, Heraeus, Hanau, Germany) as described recently [16]. 1- $\mu$ m-thick sections were cut from each slice (three to four per lung) using a Reichert Supercut 2050 and stained with eosin-hematoxylin. For ultrastructural analysis, the tissue was dehydrated through a graded series of acetone and transferred to Araldite. Ultrathin sections were counterstained with lead citrate in an Ultrostainer (Leica, Bensheim, Germany) and studied using an EM 900 (LEO, Oberkochen, Germany). Quantitative stereological analysis was performed using a Leitz Laborlux 11 (Leitz, Wetzlar, Germany) and a Zeiss Axioskop light microscope equipped with a projection tube.

\section{Stereological Analysis}

The sections were analyzed by established stereological methods using a systematic quadrats subsampling scheme to generate test fields over the whole section distributed in a systematic random fashion [9]. The time required for stereological estimation of the distinct lung parameters was about $2 \mathrm{~h}$ per lung.

For estimation of lung edema by light microscopy, an eyepiece containing an integration plate ( 25 points) was used at a final magnification of $\times 100$ to determine the volumes of parenchyma and nonparenchyma. A grid (81/12/4 points) was projected into the image level of the microscope at total magnifications of $\times 1,000$ and $\times 400$ for estimation of parenchymal and non-parenchymal components, respectively. The differential contribution of those compartments in which edema fluid was expected to accumulate was estimated by determining the volume fractions $\left(\mathrm{V}_{\mathrm{V}}\right)$ of intra-alveolar edema, septal tissue and peribronchovascular interstitium referred to total lung volume. To assess the degree of edematous swelling of the tissue compartments (septal and peribronchovascular), the $\mathrm{V}_{\mathrm{V}}$ of the corresponding lung compartments determined in the control lungs were taken as reference values. Tissue edema was then defined as the increase in $\mathrm{V}_{\mathrm{V}}$ in each experimental lung above the mean $\mathrm{V}_{\mathrm{V}}$ determined in untreated controls.

Taking into account that fluid residues in the pulmonary vascular system (composed capillaries and larger vessels) contribute to the amount of lung water which is determined by gravimetrical analysis, pulmonary intravascular water was indirectly assessed by stereological estimation of the $\mathrm{V}_{\mathrm{V}}$ of the vessel and capillary lumen:

$\mathrm{V}_{\mathrm{V}}$ intravascular water $=\mathrm{V}_{\mathrm{V}}$ vascular lumen $=\mathrm{V}_{\mathrm{V}}$ vessel lumen + $\mathrm{V}_{\mathrm{V}}$ capillary lumen.

\section{Statistics}

Data referring to individual lungs are given as discrete values obtained according to standard stereological formulas. Mean values are given \pm SEM and differences between the experimental groups were tested for significance by Kruskal-Wallis ANOVA on ranks. Provided that normality and equal variance were given, parametric one-way ANOVA was used followed by post hoc multiple comparisons (Tukey test). In terms of explorative rather than decisive data analysis, nonparametric Spearman rank order correlation and multiple regression analysis was used to test if any of the stereological parameters describing edematous accumulations was significantly associated with $\mathrm{w} / \mathrm{d}$ ratio and perfusate oxygenation, respectively. The statistical hypothesis $\left(\mathrm{H}_{0}\right)$ tested was $\mathrm{r}_{\mathrm{s}}=0$. If $\mathrm{H}_{0}$ was rejected at $\mathrm{p}<0.05$ for more than one parameter, Fisher $\mathrm{z}$ transformation was used to test if the correlation coefficients were identical $\left(r_{s 1}=r_{s 2}\right)$. The hypothesis was rejected at $\mathrm{p}<0.05$, i.e. if $\mathrm{z}>1.96$. All statistical analyses, graphic presentations and computation of regression curves were performed using the SigmaStat 2.0 and Sigmaplot 3.0 software programs (Jandel Scientific, Erkrath, Germany). $p<0.05$ was considered significant.

\section{Results}

\section{Gravimetry}

The w/d ratio was highest after preservation with Celsior at $15^{\circ} \mathrm{C}(\mathrm{CE} 15: 7.7 \pm 1.3)$ but did not show any significant differences among the experimental groups (fig. 1, EC: $6.4 \pm 1.7$; anCE: $5.4 \pm 1.2$; reCE: $5.1 \pm 0.7$; anPX: $5.1 \pm 0.6$; rePX: $5.3 \pm 0.4$; CENO: $5.1 \pm 1.3$; $\mathrm{PXNO}=5.1 \pm 1.1)$.

\section{Histology and Ultrastructure}

Qualitative Findings. Light and electron microscopy revealed edematous swelling of distinct parenchymal and non-parenchymal compartments in lungs after ischemia and reperfusion (fig. 1). Intra-alveolar edema usually occurred as small pools bordering the alveolar wall and complete flooding of alveoli was rare (fig. 1a, c, d). Swelling of 

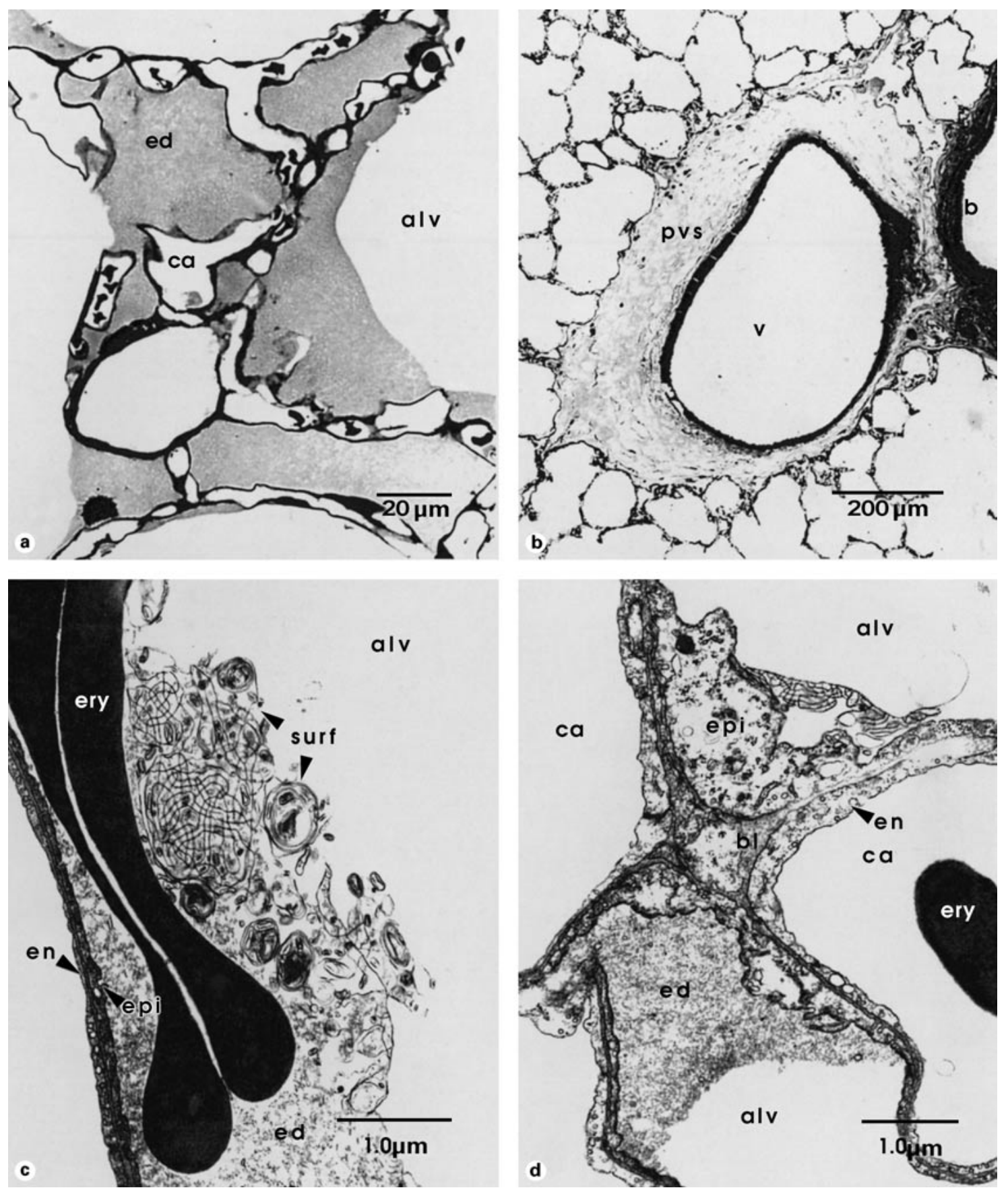

Fig. 1. Sites of pulmonary edema after ischemia/reperfusion shown by light $(\mathbf{a}, \mathbf{b})$ and electron micrographs $(\mathbf{c}, \mathbf{d})$. a Alveolus flooded by edema (ed) adjacent to an air-filled alveolus (alv). b Prominent edematous swelling of a perivascular space (pvs) confluent with bronchiolar interstitium. c Proteinaceous precipitates and erythrocytes (ery) in the alveolar hypophase between epithelium (epi) and surfactant layer (surf). d Intra-alveolar edema (ed) as well as interstitial and intracellular swelling of the alveolar septum comprising basal lamina (bl), epi- (epi) and endothelial (en) cells. $\mathrm{b}=$ Bronchiole; $\mathrm{ca}=$ capillary; $\mathrm{v}=$ vessel. 
Fig. 2. W/D ratios of lungs and $V_{V}$ of pulmonary edema and of intravascular water after ischemia/reperfusion in the distinct treatment groups. The amount of total lung edema is further differentiated into alveolar, septal and peribronchovascular edema as well as intravascular water (graph below). Data are given as mean \pm SEM.
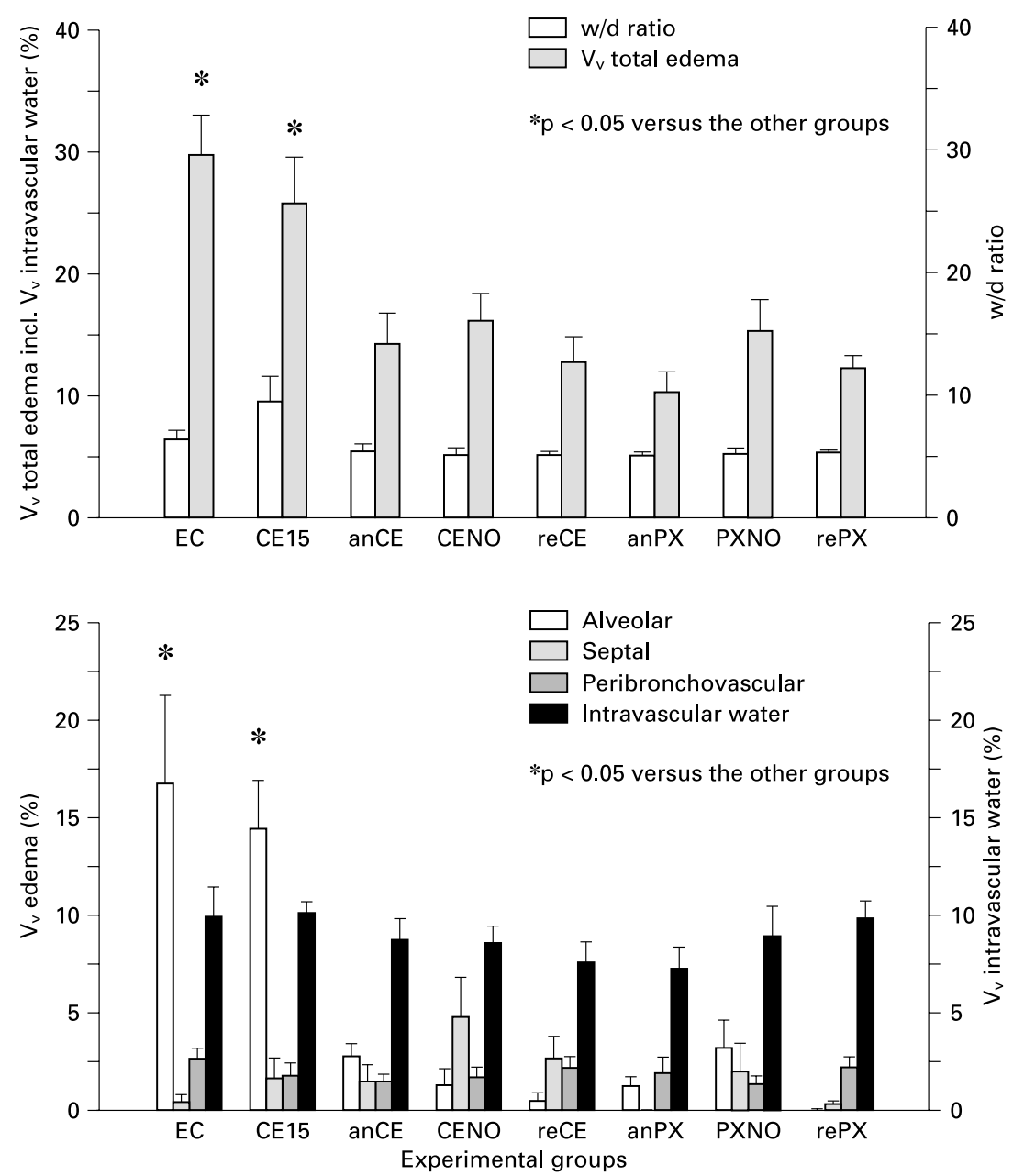

the peribronchovascular space was found in all experimental groups (fig. 1b). Within bronchovascular bundles substantially more fluid was found around arteries than airways. Edematous swelling of the alveolar wall (septal edema) was rather variable among the groups and comprised swelling of the basal lamina, the alveolar epithelial cells, the capillary endothelial cells or of only one or two of these components of the alveolar wall (fig. 1d).

Quantitative Findings. There was a marked increase $(\mathrm{p}<0.001)$ in the volume fraction $\left(\mathrm{V}_{\mathrm{V}}\right)$ of total edema including intravascular water after preservation with $\mathrm{EC}$ $(29.8 \pm 3.3 \%)$ and CE15 (27.9 $\pm 3.9 \%)$ compared with the other groups (fig. $2 \mathrm{a}$; anCE: $14.3 \pm 2.4 \%$; CENO: 16.1 $\pm 2.3 \%$; reCE: $12.8 \pm 2.0 \%$; anPX: $10.4 \pm 1.6 \%$; PXNO: $15.3 \pm 2.5 \%$; rePX: $12.2 \pm 1.1 \%$ ).
The distribution pattern of edema fluid in the distinct lung compartments (alveoli, alveolar walls, peribronchovascular spaces) revealed a marked accumulation ( $p<$ 0.001) of edema fluid in the alveoli in the CE15 and EC groups (fig. $2 b$; CE15: $14.5 \pm 2.4 \%$; EC: $16.8 \pm 4.5 \%$ ) compared to all other groups (anCE: $2.7 \pm 0.6 \%$; reCE: $0.5 \pm 0.4 \%$; anPX: $1.2 \pm 0.5 \%$; rePX: not found; CENO: $1.3 \pm 0.8 \%$; PXNO: $3.1 \pm 1.5 \%$ ). Alveolar edema became negligibly small in retrogradely perfused lungs. The $V_{V}$ of septal and peribronchovascular edema did not differ significantly among the groups. The $\mathrm{V}_{\mathrm{V}}$ of the intravascular lumen (capillaries plus larger vessels) which is an indirect parameter to assess water residues in the pulmonary arterial and venous system, did not show any significant differences among the groups tested (fig. 2b). 

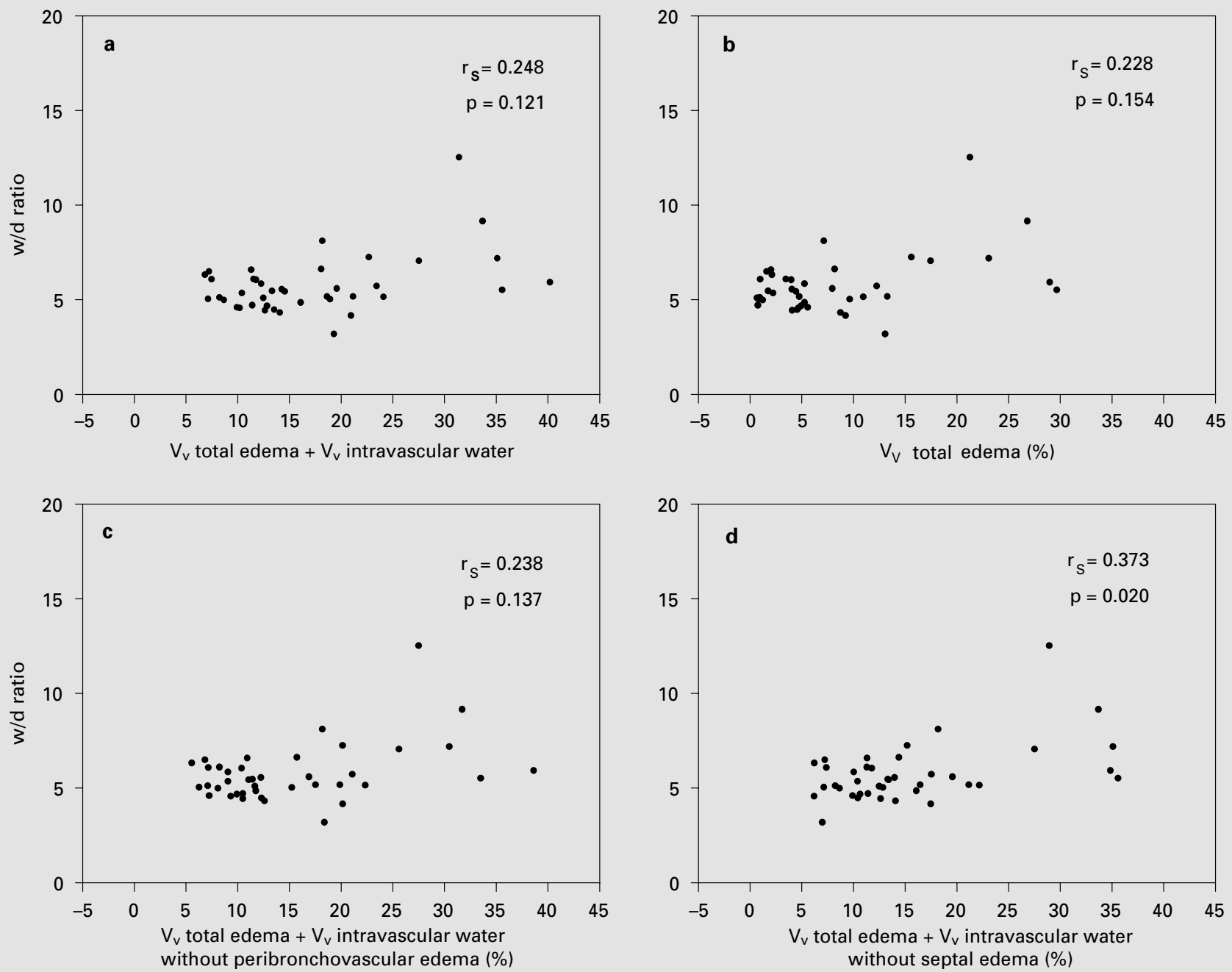

without septal edema (\%)
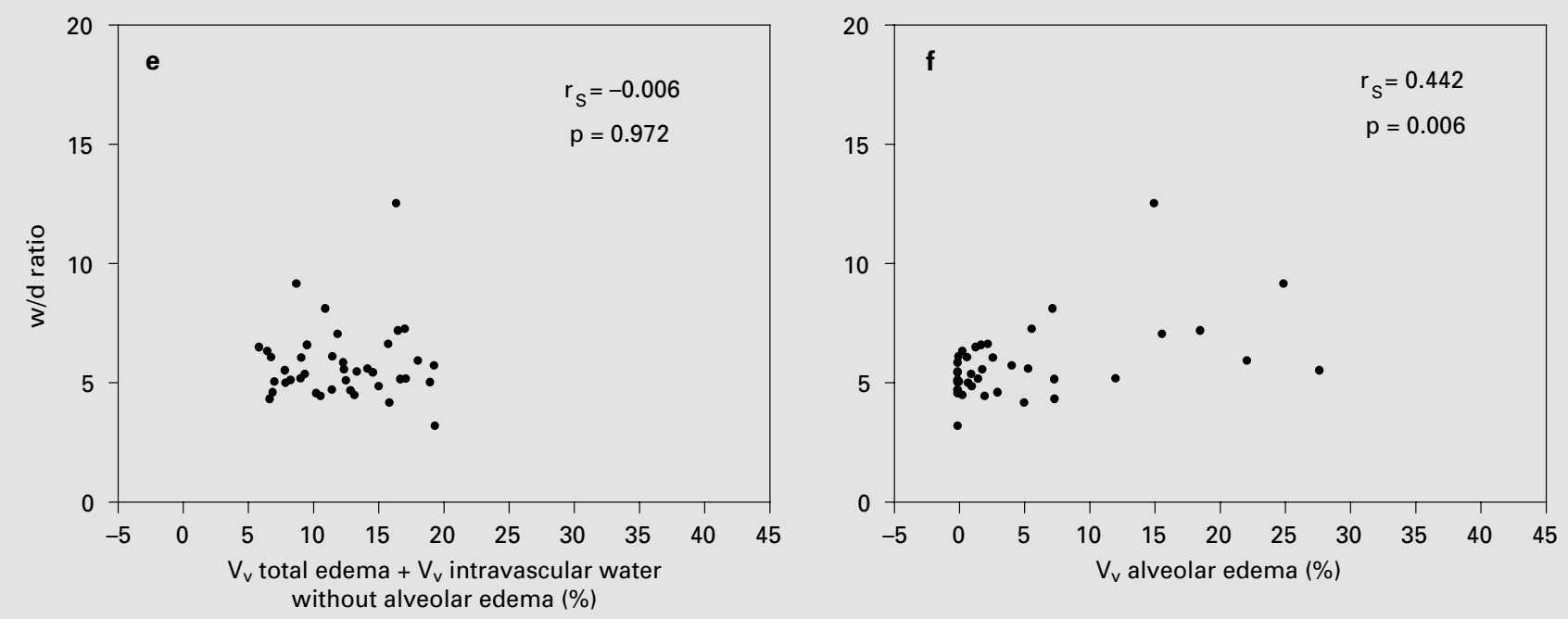

Fig. 3. Relationship between $w / d$ ratio and the $V_{V}$ of lung edema including or excluding distinct edematous or fluid accumulating compartments. The coefficient of correlation $\left(\mathrm{r}_{\mathrm{S}}\right)$ derives from Spearman rank order correlation; $\mathrm{p}<0.05$ is considered to be significant. 


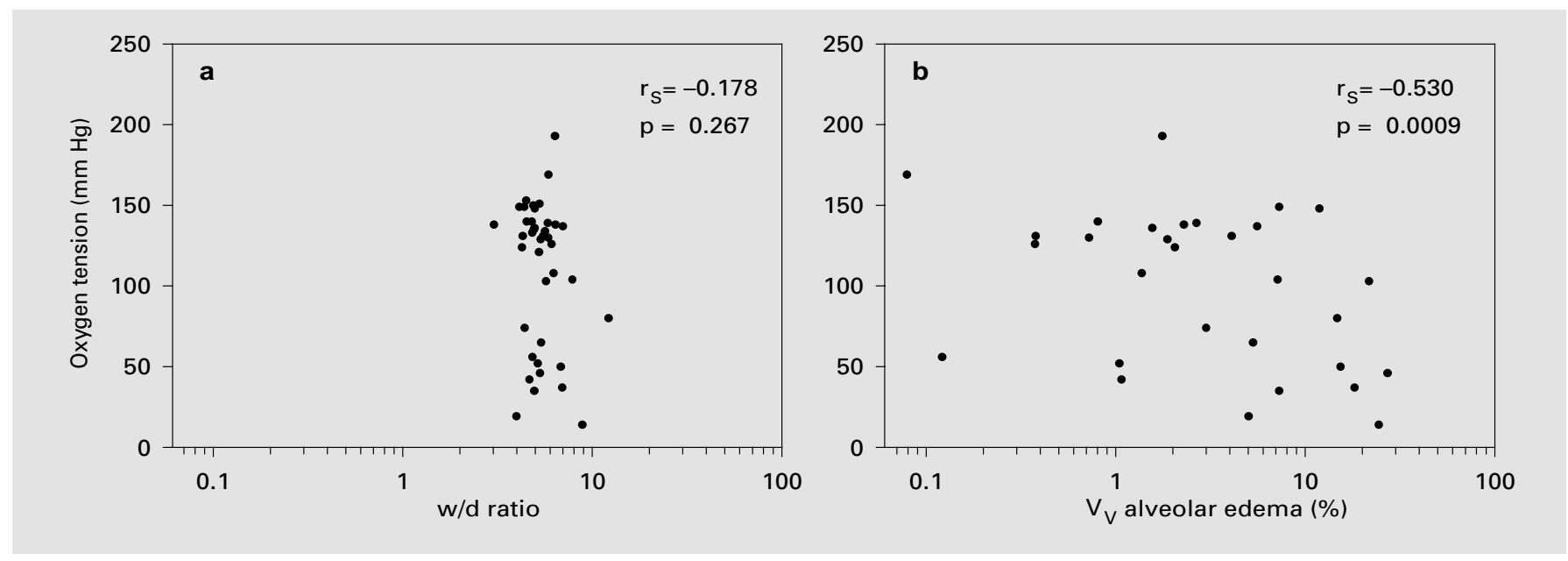

Fig. 4. Relationship between oxygen tension at the end of reperfusion, $w / d$ ratio $(\mathbf{a})$ and the $V_{V}$ of alveolar edema (b). The coefficient of correlation $\left(r_{S}\right)$ derives from Spearman rank order correlation. Since the relationship between oxygen tension and alveolar edema is not linear, the $\mathrm{x}$-axis is given in logarithmic scales.

\section{Correlations}

To assess the relationship between the $\mathrm{w} / \mathrm{d}$ ratio and the stereologically determined volume fraction $\left(\mathrm{V}_{\mathrm{V}}\right)$ of edema, the data of all experimental groups were pooled and rank order correlation as well as multiple regression analysis of the variables was performed. The w/d ratio was correlated with the $\mathrm{V}_{\mathrm{V}}$ of edema of each compartment and of the intravascular water, separately. Forward stepwise regression analysis revealed significant correlation only between the $\mathrm{V}_{\mathrm{V}}$ of alveolar edema and the w/d ratio $(\mathrm{p}<0.01)$ which was also documented by nonparametric rank order correlation (fig. 3f; $r_{s}=0.442, p=0.0057$ ). In addition, the correlation between $\mathrm{w} / \mathrm{d}$ ratio and $\mathrm{V}_{\mathrm{V}}$ of total edema including intravascular water which was not significant (fig. 3a; $r_{s}=0.248, p=0.121$ ), markedly deteriorated when the values of alveolar edema were excluded (fig. 3e; $r_{s}=-0.006, p=0.972$ ). In contrast, correlation between total edema plus intravascular water and the w/d ratio (fig. $3 \mathrm{a} ; \mathrm{r}_{\mathrm{s}}=0.248, \mathrm{p}=0.121$ ) became significant when septal edema was excluded from the calculation (fig. $3 \mathrm{~d} ; \mathrm{r}_{\mathrm{s}}=0.373, \mathrm{p}=0.020$ ) indicating that edematous swelling of the alveolar wall were not reflected by the w/d ratio. However, exclusion of intravascular water (fig. 3b; $\left.\mathrm{r}_{\mathrm{s}}=0.228, \mathrm{p}=0.154\right)$ as well as of the peribronchovascular edema (fig. $3 c ; r_{s}=0.238, p=0.137$ ) did not have any influence on the relationship between the parameters.

\section{Structure-Function Relationships}

To validate the different estimators of edema formation, oxygenation of the perfusate is the most important parameter. The w/d ratio did not correlate significantly with oxygen tension measured after $50 \mathrm{~min}$ of reperfusion (fig. $4 \mathrm{a} ; \mathrm{r}_{\mathrm{s}}=-0.178, \mathrm{p}=0.267$ ). However, oxygen tension markedly decreased with increasing $\mathrm{V}_{\mathrm{V}}$ of alveolar edema (fig. $4 b ; r_{s}=-0.530, p=0.001$ ).

\section{Discussion}

The determination of the w/d weight ratio by gravimetrical analysis is currently being used as an indirect measurement of fluid accumulation during IR injury in the experimental setting [17-20]. Evaluation of the severity of edema formation can be improved by coupling the information from two or more parameters such as amount and anatomic distribution of extra- and intravascular water in the distinct lung compartments [7]. The advantage of the stereological approach compared to gravimetry is that edematous compartments can be distinguished morphologically and can therefore be evaluated separately from the remaining water bodies of the lung. While 'lung water' is determined using the gravimetrical assessment, stereological analysis quantifies 'lung edema'. We therefore hypothesized that stereological assessment of lung edema is more specific than gravimetry since it allows for both, exclusion of intravascular lung 
water and distinction between interstitial and intraalveolar edema.

Stereological analysis of a collection of tissue samples representative of the whole lung was earlier shown to validly quantify accumulations of edema fluid for the distinct compartments of the organ $[11,13,21]$. Compared to morphometrical studies on serially sectioned tissue samples, stereology is more efficient since it provides reliable data in a shorter period of time. An important prerequisite to quantify tissue parameters at the microscopic level is an adequate fixation of the proteinaceous and fibrous skeleton. Although cryofixation is considered to be the best means to avoid tissue shrinkage due to loss of fluid [22], it does not allow for stereological sampling. Previous studies clearly demonstrated that pulmonary edema can be validly quantified in chemically fixed tissue samples by light microscopy [7, 23-25]. After dehydration alveolar edema is preserved as proteinaceous intraalveolar precipitates which indicate the former fluid level in the alveolar lumen. Adequate preservation of edema accumulation has been achieved by sequential processing using a glutaraldehyde/paraformaldehyde containing primary fixative and osmium tetroxide and uranyl acetate as postfixatives [26]. If there is still residual shrinkage, it should be overproportionate in the more hydrous compartments, i.e. intra-alveolar fluid (less proteins, less stable) resulting in an underestimation of alveolar edema compared to tissue edema. Additionally, residual shrinkage of the fibrous skeleton of septal and peribronchovascular interstitium due to tissue retraction should be taken into consideration $[26,27]$. The combination of two fixatives, the transpulmonary pressure of $40 \%$ total lung capacity and embedding in methacrylate resin instead of paraffin were chosen to reduce tissue retraction. Taking into account these standardized experimental conditions, shrinkage due to tissue retraction should be similar in all groups. Tissue edema was then defined as the increase in $\mathrm{V}_{\mathrm{V}}$ in each experimental lung above the mean $\mathrm{V}_{\mathrm{V}}$ determined in untreated controls. Thus, the volume fractions $\left(\mathrm{V}_{\mathrm{V}}\right)$ of septal and peribronchovascular compartments were normalized to control values.

A central statement from the present study is that the $\mathrm{w} / \mathrm{d}$ ratio is determined predominantly by the amount of intra-alveolar edema, which could be estimated by stereological quantification of proteinaceous intra-alveolar precipitates at the light-microscopic level. However, the w/d ratio did not reveal the significant group specific differences in intra-alveolar edema formation as assessed by stereology. The functional relevance of the amount of intra-alveolar fluid accumulation could only be docu- mented in comparison with the stereologically but not gravimetrically determined values.

Fluid accumulations in the alveolar septum do not appear to be recorded by the w/d ratio. This is based on the finding that the correlation between $\mathrm{w} / \mathrm{d}$ ratio and stereologically estimated lung edema became significant when the amount of septal edema was excluded. Septal tissue only comprises $8-12 \%$ of the total lung volume and is therefore considered as a compartment of minor contribution to changes in the $\mathrm{w} / \mathrm{d}$ ratio whereas swelling of endothelial and epithelial cells can be registered by stereology. Similarly, the peribronchovascular space forms a small part (1-5\%) of total lung volume and the occurrence of perivascular edema, although significant after IR, may not substantially influence w/d ratio values. A contribution of intravascular water to the w/d ratio could not be documented, although the values determined by stereology were relatively high. We conclude that gravimetrical analysis of lung tissue is specifically determined by the amount of intra-alveolar edema but that changes in intracellular as well as interstitial fluid accumulation are not registered by the $\mathrm{w} / \mathrm{d}$ ratio. We suggest that the differences among the treatment groups are abolished due to variabilities in the drying process of the tissue during gravimetry.

The accuracy of the w/d ratio is affected by three technical problems: the method of drying the specimens, the water content of the residual blood, and changes in dry weight [28]. The particular drying procedure is not critical as long as one is certain that the specimen has been given time to completely dry and no component other than water was vaporized. The sensitivity of the method can be improved by correction for the water content of residual blood which allows for calculation of the extravascular water volume [28, 29]. We therefore assume that the procedure for w/d ratio determination usually applied which was also used in this study, may be insufficient to detect experimentally induced changes in the formation of lung edema. Alternatively, drying in a microwave oven which is faster and more controlled or a vacuum drying technique which, however, requires 9-17 days, may be more reliable [29].

Referring to pulmonary water content these indirect gravimetrical methods are not only relatively insensitive to real increases in lung water but they are totally insensitive in terms of detecting increases in transvascular fluid and protein flow [28]. These can be achieved by direct measurement of changes in lung weight which, however, cannot monitor variations in extravascular lung water unless blood volume is measured independently [5]. In 
contrast, the stereological approach allows for differential assessment of both intra- and extravascular lung water.

Our findings demonstrate that stereologically estimated lung edema is of functional relevance which proves the high specificity of edema assessment by stereology. Based on these methods, marked differences in the preservation quality of the distinct solutions and applications were found $[11,13,21]$.

In conclusion, the w/d ratio is mainly determined by the amount of intra-alveolar edema. However, gravimetry is less accurate in determination of lung edema and is of minor functional relevance compared with assessment by stereological methods. Stereology proves to be a reliable and efficient tool for the evaluation of IR injury in the different experimental settings.

\section{Acknowledgements}

The writers gratefully acknowledge the expert technical assistance of M. Fathollahy, K. Sommer, S. Freese, A. Gerken, and H. Hühn. They also thank C. Maelicke for reading the English version of the manuscript. The study was supported by the Deutsche Forschungsgemeinschaft (Wa 738/3-4; Ri 790/1-4).

\section{References}

1 Matthay MA, Ingbar DH: Pulmonary edema; in Lenfant C (ed): Lung Biology in Health and Disease. New York, Marcel Dekker, 1998.

2 Khan SU, Salloum J, O’Donovan PB, Mascha EJ, Mehta AC, Matthay MA, Arroliga AC: Acute pulmonary edema after lung transplantation: The pulmonary reimplantation response. Chest 1999;116:187-194.

3 Staub NC, Nagano H, Pearce ML: Pulmonary edema in dogs, especially the sequence of fluid accumulation in lungs. $\mathbf{J}$ Appl Physiol 1967;22: 227-240.

4 Staub NC: Alveolar flooding and clearance. Am Rev Respir Dis 1983;127:S44-S51.

5 Bayat S, Grimbert F: Experimental and clinical measurement of pulmonary edema; in Uhlig $\mathrm{S}$, Taylor AE (eds): Methods in Pulmonary Research. Basel, Birkhäuser, 1998, pp161-229.

6 Peterson BT: Permeability: Theory vs. practice in lung research. Am J Physiol 1992;262:L243256.

7 Michel RP, Meterissian S, Poulsen RS: Morphometry of the distribution of hydrostatic pulmonary oedema in dogs. Br J Exp Pathol 1986; 67:865-877.

8 Fehrenbach $\mathrm{H}$, Ochs M: Studying lung ultrastructure; in Uhlig S, Taylor AE (eds): Methods in Pulmonary Research. Basel, Birkhäuser, 1998, pp 429-454.

9 Howard CV, Reed MG: Unbiased Stereology. Three-Dimensional Measurement in Microscopy. Oxford, Bios, 1998, pp 1-246.

10 Fehrenbach A, Ochs M, Warnecke T, Wahlers T, Wittwer T, Schmiedl A, Elki S, Meyer D, Richter J, Fehrenbach H: Beneficial effect of lung preservation is related to ultrastructural integrity of tubular myelin after experimental ischemia and reperfusion. Am $\mathrm{J}$ Respir Crit Care Med 2000;161:2058-2065.

11 Fehrenbach H, Schepelmann D, Albes JM, Bando T, Fischer F, Fehrenbach A, Stolte N, Wahlers T, Richter J: Pulmonary ischemia/ reperfusion injury: A quantitative study of structure and function in isolated heart-lungs of the rat. Anat Rec 1999;255:84-89.
12 Ochs M, Nenadic I, Fehrenbach A, Albes JM, Wahlers T, Richter J, Fehrenbach H: Ultrastructural alterations in intra-alveolar surfactant subtypes after experimental ischemia and reperfusion. Am J Respir Crit Care Med 1999; 160:718-724.

13 Wittwer T, Wahlers T, Fehrenbach A, Elki S, Haverich A: Improvement of pulmonary preservation with Celsior and Perfadex: Impact of storage time on early post-ischemic lung function. J Heart Lung Transplant 1999;18:11981201.

14 Wittwer T, Wahlers T, Fehrenbach A, Cornelius JF, Elki S, Ochs M, Fehrenbach H, Albes J, Haverich A, Richter J: Combined use of prostacyclin and higher perfusate temperatures further enhances the superior lung preservation by celsior solution in the isolated rat lung. J Heart Lung Transplant 1999;18:684-692.

15 Ochs M, Fehrenbach H, Nenadic I, Bando T, Fehrenbach A, Schepelmann D, Albes JM, Wahlers T, Richter J: Preservation of intraalveolar surfactant in a rat lung ischaemia/reperfusion injury model. Eur Respir J 2000;15: 226-231.

16 Fehrenbach A, Ochs M, Wittwer T, Cornelius J, Fehrenbach H, Wahlers T, Richter J: Stereological estimation of the volume weighted mean volumes of alveoli and acinar pathways in the rat lung to characterise alterations after ischaemia/ reperfusion. J Anat 1999;194:127-135.

17 Yamagishi H, Yamashita C, Okada M: Preventive influence of inhaled nitric oxide on lung ischemia-reperfusion injury. Surg Today 1999;29:897-901.

18 Fukahara K, Murakami A, Watanabe G, Kotoh $\mathrm{K}$, Misaki $\mathrm{T}$ : Inhaled nitric oxide after lung ischemia reperfusion: Effect on hemodynamics and oxygen free radical scavenger system. Eur J Cardiothorac Surg 1997;11:343-349.

19 DeLima NF, Binns OA, Buchanan SA, Mauney MC, Cope JT, Shockey KS, Tribble CG, Kron IL: Euro-Collins solution exacerbates lung injury in the setting of high- flow reperfusion. J Thorac Cardiovasc Surg 1996;112:111116.
20 Khimenko PL, Barnard JW, Moore TM, Wilson PS, Ballard ST, Taylor AE: Vascular permeability and epithelial transport effects on lung edema formation in ischemia and reperfusion. J Appl Physiol 1994;77:1116-1121.

21 Fehrenbach A, Wittwer T, Cornelius J, Ochs M, Fehrenbach H, Wahlers T, Richter J: Improvement of rat lung structure and function after preservation with Celsior. J Surg Res 1999;82:285-293.

22 Bastacky J, Lee CY, Goerke J, Koushafar H, Yager D, Kenaga L, Speed TP, Chen Y, Clements JA: Alveolar lining layer is thin and continuous: Low-temperature scanning electron microscopy of rat lung. J Appl Physiol 1995;79: 1615-1628.

23 Wu DX, Weibel ER, Bachofen H, Schürch S: Lung lesions in experimental hydrostatic pulmonary edema: An electron microscopic and morphometric study. Exp Lung Res 1995;21: 711-730.

24 Zwikler MP, Peters TM, Michel RP: Effects of pulmonary fibrosis on the distribution of edema: Computed tomographic scanning and morphology. Am J Respir Crit Care Med 1994; 149:1266-1275.

25 Bachofen H, Schürch S, Michel RP, Weibel ER: Experimental hydrostatic pulmonary edema in rabbit lungs: Morphology. Am Rev Respir Dis 1993;147:989-996.

26 Bachofen H, Ammann A, Wangensteen D, Weibel ER: Perfusion fixation of lungs for structure-function analysis: Credits and limitations. J Appl Physiol 1982;53:528-533.

27 Mazzone RW, Kornblau S, Durand CM: Shrinkage of lung after chemical fixation for analysis of pulmonary structure-function relations. J Appl Physiol 1980;48:382-385.

28 Staub NC: Pulmonary edema. Physiol Rev 1974;54:678-811.

29 Peterson BT, Brooks JA, Zack AG: Use of microwave oven for determination of postmortem water volume of lungs. J Appl Physiol 1982;52:1661-1663. 